\title{
The Spatial Range of Public Goods Revealed Through Referendum Voting
}

\author{
Robert T. Deacon • Felix Schläpfer
}

Accepted: 2 May 2010 / Published online: 22 May 2010

(C) The Author(s) 2010. This article is published with open access at Springerlink.com

\begin{abstract}
Billions of dollars are now spent annually in the United States and Europe for spatially delineated environmental services such as agricultural landscape management and river restoration programs, yet little is known about the spatial distribution of the benefits from these policies. This paper develops a framework for recovering information on this question from the spatial pattern of votes cast for referenda on the provision of spatially delineated public goods. We specify a model linking voter support for environmental improvement to the distance at which such improvements are expected to occur. The empirical application is to a river restoration referendum in the Swiss canton of Bern. Our results indicate that the benefits from river restoration have a strong local component, sufficiently strong that voter approval would not occur if only canton-wide benefits were at stake. Surprisingly, support for river restoration is no greater, and in some specifications is actually lower, in locations where rivers are a prominent feature in the environment.
\end{abstract}

Keywords Voting $\cdot$ Revealed preference $\cdot$ Spatial range of environmental amenities

\section{Introduction}

Many traditional public services such as ambulances or national defence have benefits accruing to fairly well-defined local, state or national populations. However, there is a range of more recent public policy interventions with a distinct spatial dimension, many related to

\footnotetext{
R. T. Deacon ( $\varangle)$

Department of Economics, University of California, Santa Barbara, CA 93106, USA

e-mail: deacon@econ.ucsb.edu

F. Schläpfer

Socioeconomic Institute, University of Zurich, Zurich, Switzerland

F. Schläpfer

Institute for Environmental Decisions, Federal Institute of Technology ETH, Zurich,

Switzerland
} 
aspects of environmental quality, for which the spatial distribution of benefits is not obvious. Environmental examples are the restoration of natural habitats and protection of endangered species and ordinary wildlife. Individuals value such programs, even though they necessarily occur apart from where people actually live. Examples from an urban setting include community redevelopment, planning programs and crime reduction initiatives.

It seems useful to distinguish two levels at which questions regarding the spatial analysis of benefits can be addressed, each with its specific applied potential.

The first, qualitative level concerns the spatial range over which any willingness to pay (WTP) for the local public good is observed or, in other words, the "extent of the market". Information about the spatial range of benefits alone (without quantification of these benefits) would be useful for assigning responsibilities to appropriate levels of government in a federal state. If the jurisdictions responsible for decision-making and financing of a public service reflect the range and distribution of its benefits, then efficient provision is compatible with democratic decision-making (Oates 1972; Cornes and Sandler 1996; Loomis 2000). Additionally, the spatial extent of damages from environmental degradations is a controversial and contentious question that arises in assessing natural resource damages. According to Smith (1993, p. 21) "Definitions of the extent of the market are probably more important to the values attributed to environmental resources as assets than any changes that might arise from refining our estimates of per unit values."

The second, quantitative level of analysis is more demanding and concerns the magnitude of willingness to pay as a function of the distance and quantity or "scope" of the spatially delineated resource damage or improvement. Such information is needed if the purpose of the analysis is to obtain monetary estimates of resource damages or benefits of proposed policies. How do individuals value the distance and quantity or abundance of any resource to be protected? Intuition suggests that an individual would be willing to pay more to raise a resource to any given level of quality if the resource is close to the individual and if the extent of the resource is large rather than small. For instance, raising the quality of local rivers to a pristine level would seem more important if rivers are close to settlements and if they dominate the landscape than if they are distant and relatively inconsequential in scope. While this reasoning may be plausible, the question cannot be answered without empirical evidence.

There are in principle several options for addressing empirical questions on the spatial distribution (and basic character) of such preferences. Perhaps the most frequently used method for the generic problem of measuring public good benefits is contingent valuation, in which surveyors ask respondents their willingness to pay for hypothetical variations in a public good. Hedonic wage and housing price studies constitute a second approach, in which values are inferred from the price differential individuals pay or receive for public goods consumed as a consequence of living in a certain neighbourhood or working at a certain job. A third method, based on a specific political model, links attributes of a jurisdiction's median citizen with public good outcomes. Each of these approaches has been criticised on various grounds (Kahn and Matsusaka 1997). We are unaware, however, of any study that has examined the spatial nature of benefits with results from referendum voting.

Relying on ballot choices is attractive in cases where public good levels are decided by referenda. In such cases, the individual's voting choice reveals a preference. Observations on these revealed preferences, together with relevant prices and individual attributes, can in principle provide information on benefits received in the same way that individual consumption choices reveal benefits in a conventional market setting (Bowen 1943; Deacon and Shapiro 1975; Noam 1981; Kahn and Matsusaka 1997). The electoral process often provides information on the pros and cons of different ballot options prior to elections, so voters are 
exposed to relevant information. There is no need to assume that the good in question can be enjoyed only by those who reside in a particular location or are employed in a particular job. Finally, one need not invoke a particular theory of political outcomes in order to draw inferences; an assumption that individuals are informed and vote in their self interest is sufficient.

Our aim is thus to develop and apply a framework for analyzing the basic character and spatial distribution of benefits for a spatially heterogeneous public good, based on preferences revealed through voting on referenda. Unlike most empirical voting studies we do not assume that all voters consume the same level of public good ex ante, or that they face exactly the same potential public good augmentation. Rather, we incorporate the fact that pre-policy public good levels generally differ across space and also allow voters' expectations on public good augmentations to vary spatially. Further, the public good we examine is restoration of an environmental resource to a more natural quality, and the abundance of this resource varies spatially as well. By exploiting this spatial variation in abundance, or quantity, we also shed light on how ex ante quality and quantity interact in determining the value individuals place on restoration of the resource.

The paper proceeds as follows. Section 2 briefly reviews the relevant literature on voting models and spatial analysis of public good benefits. Section 3 develops the empirical model for the specific context of river restoration. Section 4 presents the empirical application and Section 5 concludes.

\section{Background}

\subsection{Spatial Distribution of Public-good Benefits}

Two main approaches have so far been used to examine the spatial distribution of the benefits of public goods, the hedonic pricing technique and contingent valuation.

Hedonic property pricing models are particularly appropriate to the task as they specifically reveal buyers' preferences over housing attributes, including local public goods. Geographic information systems (GIS) can be used to construct variables for local public goods based on spatial relationships between the observed properties and the public goods of interest. A number of studies used this approach to estimate the benefits of proximity to open space (Irwin 2002; Geoghegan et al. 1997; Geoghegan 2002; Acharya and Bennett 2001). All of these found that, when compared to residential, commercial or industrial uses, open space located within a given distance from a property has a positive impact on property price. Another series of studies found that house prices were negatively affected by animal production facilities within given distances (Abeles-Allison and Connor 1990; Palmquist et al. 1997; Herriges et al. 2005; Ready and Abdalla 2005). Several studies found that the observed effects depended on the distance between the individual house and the environmental effect examined (e.g. Palmquist et al. 1997; Geoghegan et al. 1997; Mahanet al. 2000; Acharya and Bennett 2001; Ready and Abdalla 2005). This literature is reviewed in Ready and Abdalla (2005). However, an important limitation of these studies is that they are only able to recover values to the extent they are reflected in housing prices.

Contingent valuation (CV) can in principle be applied to any type and spatial scale of public goods. Loomis (2000) includes distance to policy sites in models of stated WTP for wildlife protection programs. Using the estimated distance-decay parameters he computes the percentage of total economic benefits that fall within the relevant state or regional jurisdictions. Other studies that estimated benefits based on distance decay functions include Pate 
and Loomis (1997), Pate and Loomis (1997), Bateman et al. (1997), Bateman et al. (2000) and Bateman et al. (2006). However, when validity tests are built into survey designs, researchers sometimes find that stated willingness to pay for improvements seems to decay too slowly with distance to be consistent with economic theory. Hanley et al. (2003) found that the distance-decay of stated WTP for improving one arbitrarily selected river of the Thames region implied aggregate values that were substantially higher than the benefits implied by the same respondents' stated values for improving all rivers of the region. This result is closely related to findings in the literature on "scope effects" or "embedding effects" in CV which addresses effects of the quantity of a good more generally (rather than of its spatial dimensions). ${ }^{1}$

Furthermore, proximity to environmental resources has been an issue in the literature on the appropriate extent and definition of the market in cost-benefit analysis based on hedonic models (e.g. Michaels and Smith 1990) and models of recreation demand (e.g. Smith and Kopp 1980; Whittington and MacRae 1986; McConnell 1990; Phaneuf and Smith 2005). In the analysis of recreation demand, the definition of the choice sets and (perceived) geographic extent of the market have been found to strongly affect welfare estimates, raising important questions about the correct conceptual treatment of researcher-defined or endogenous choice sets or choice boundaries (Parsons 1991; Parsons et al. 2000; Phaneuf and Smith 2005).

Voter preferences have not been systematically used for assessing the spatial range and distribution of the benefits of natural resources. In the analysis of voter preferences for spatially explicit public goods, the examined market and choice set is clearly defined by the boundaries of the jurisdiction making the decision about financing and by the public good proposal. Due to this distinctive characteristic, the analysis of voter preferences has the potential to provide insights about the spatial distribution of willingness to pay for public goods complementing results from other approaches.

\subsection{Voting Models}

Two of the earliest studies to use voting data to infer public good demand are Deacon and Shapiro (1975) and Fischel (1979), both of which yielded suggestive but promising results from state-wide environmental referenda. In another early study Rubinfeld (1977) examined individual voting data on an educational referendum and estimated the relative effects of income and tax obligation on voting choices. More recently, Kline and Wichelns (1994) related voting returns on open space referenda in Pennsylvania and Rhode Island to such socioeconomic determinants as housing price appreciation, population growth, and farmland loss. Kahn and Matsusaka (1997) subsequently examined votes from 16 environmental propositions, focusing on the role of income as a determinant of votes cast and on factors linked to the costs a policy imposes. Kotchen and Powers (2006) and Nelson et al. (2007) extended the literature by examining determinants of the overall vote totals for a large number of open space referenda, emphasizing the factors that contribute to the appearance of such referenda as well as the effect of funding mechanisms on voter approval. ${ }^{2}$ While the main intent of the preceding studies was to better understand the factors that influence public good demands, other researchers have examined voting data with the intent of validating CV estimates of environmental benefits. Schläpfer and Hanley (2006) developed a method for recovering

\footnotetext{
1 McFadden (1994), for instance, finds that WTP for 57 wilderness areas was only about fifty percent higher than WTP for one wilderness area alone. However, Smith and Osborne (1996) clarify that all we can say is that the WTP for a larger amount of a resource should be greater or equal to the WTP for a smaller amount.

2 Noam $(1981,1982)$ modelled both the decision of whether to vote or abstain and the ballot choice if a vote was cast. The resulting approach was used to examine demands for a variety of public goods in Swiss cantons.
} 
willingness to pay from aggregate voting data and tax schedules and compared the resulting estimates to $\mathrm{CV}$ results.

None of these studies has examined the spatial pattern of votes in connection with spatial variation in public good provision. Kotchen and Powers (2006) find that outcomes vary for different levels of government and interpret this as suggesting spatial spill-ins between jurisdictions and a spatial dimension to open space benefits. They do not pursue this point, however. Vossler and Kerkvliet (2003) consider a potential role of distance to the proposed local public good. However, they include distance only in sub-models to explain participation in their survey (where distance turned out to be non-significant), and not in the analysis of the respondents' reported voting choices. Schläpfer and Hanley (2003) and Schläpfer and Witzig (2006) use ad-hoc specifications to relate approval rates in voting decisions about the provision of public goods to local levels of these public goods. The former study found that increased public financing of landscape amenities was positively associated with local (municipal) levels of these amenities. The latter study related local support for regional-level river restoration to local river "naturalness" as measured by eco-morphological data. The authors find some evidence supporting the hypothesis that demand increases with decreasing naturalness of local rivers.

We contribute to this literature by developing a model that permits inferences on the spatial range of public goods to be drawn from the spatial pattern of votes on public good enhancement. The specific context we examine is a public referendum to restore rivers to a more natural state in the Swiss canton of Bern. While the model we develop is formulated with this policy in mind, it may be applicable to other situations where public good provision has a clear spatial component, such as flood control, open space preservation, or even the introduction of large predators. ${ }^{3}$ This framework is then applied to the river restoration dataset of Schläpfer and Witzig (2006) and the questions posed earlier, regarding the effect on WTP of distance from the voter and the local abundance of the resource to be restored, are examined empirically.

The present study moves beyond the descriptive analysis of Schläpfer and Witzig (2006) by specifically testing for evidence of a spatial (distance) gradient in public good amenity benefits. We develop an analytical framework that links three important ingredients to the individual's voting decision: the individual's tax liability from the proposed tax policy, the ex ante quality and quantity of river segments at different distances from the voter, and the degree of expected enhancement for these river segments. This framework sheds light on the rate at which public good benefits diminish (if at all) with distance from the voter and can in principle identify the spatial limit at which they disappear. The model formalizes certain intuitive arguments made in Schläpfer and Witzig (2006), but also has a broader set of implications and leads to different empirical specifications and interpretations of results. Under the hypothesis that enhancement benefits decline with distance, the empirical model specifies that yes votes depend on the quality and abundance of rivers (separately and interacted) in various non-overlapping distance zones from the voter. Tests of the local public good hypothesis are then based on the partial derivative of yes votes with respect to quality in successive zones. ${ }^{4}$ In further tests, we allow for the possibility that the benefits of river enhancement differ between urban and more rural environments and consider linear and threshold effects of the amenity's abundance. We use a more carefully derived set of control

\footnotetext{
${ }^{3}$ I this last example, the spatial relationship may not be monotonic. However, our model does not require a particular monotonic relationship, but rather allows the distance/value relationship to have any shape.

4 Such tests are not possible in the specification of Schläpfer and Witzig (2006), which includes average river quality in a single distance zone.
} 
variables in all specifications, including fixed effects for administrative districts to allow for spatial heterogeneity, as well as variables for percent owner occupied housing (to allow for the possibility that voters expect enhancement benefits to be capitalized into property values) and for employment in the construction industry. Finally, to indicate the importance of a local component to river enhancement we compute predicted voting outcomes under a counter factual situation in which voters expect the referendum to have no effect on local river quality, but to affect river quality elsewhere. These results indicate that the local component of river enhancement benefits was decisive to the referendum's passage.

\section{Model}

The spatial distribution of votes should reflect the spatial distribution of benefits voters perceive from improving river quality at various distances from where they live. ${ }^{5}$ For example, suppose the quality of a single river is to be improved and river quality is a nationwide public good so the benefits consumers experience are independent of their distance from the improvement. In this case, assuming identical tastes, incomes and tax liabilities, voters at all locations will be equally likely to vote in favour of restoring this single river. Alternatively, if river quality is a local public good so the benefits from improvement diminish with distance, then those living near the river will be more inclined to vote for an improvement than those living far away.

Similar reasoning can be applied to the spatial pattern of voting on a nationwide referendum that would enhance river quality at all locations. If river quality is a nationwide public good then (assuming identical incomes, tastes, etc.) voters living near degraded rivers and voters living near pristine rivers will be equally likely to vote in favour. This is true because river enhancement at any location would confer identical benefits on all voters, regardless of where they live. If the benefits from enhancement decline with distance from the voter, however, voters living near degraded rivers will be more likely to vote for the proposal than those living near pristine rivers. There are two reasons for this: voters near degraded rivers are likely to have a high marginal utility for improvement, and (at least in the context we examine) the proposed policy is likely to yield greater improvement for degraded rivers than for more pristine rivers.

Our empirical strategy follows this reasoning. We model the individual's voting decision in such a way that, controlling for tastes, incomes and tax liabilities, the correlation between yes votes and the ex ante quality of rivers in the voter's local area can be interpreted as evidence on the local versus nationwide character of river enhancement benefits. Along the way, we introduce a feature that allows us to address the question of whether or not preferences for river restoration depend on the 'quantity' or extent of nearby rivers that would be restored. We recognize the possibility that variations in local river quality might be capitalized in housing prices, in which case votes for and against a quality enhancement would depend on factors other than the utility the voter gets from a quality improvement; in particular, the voting choice might depend on whether the voter is a net demander or net supplier of housing. For the sake of simplicity we do not incorporate this feature in our model, but we do allow for it informally in our empirical specification. ${ }^{6}$ Throughout, we assume that residents vote

5 The referendum we examine sought to enhance the 'naturalness' of rivers by altering river beds and embankments toward a more natural condition. Because the term naturalness is somewhat awkward, we often use 'quality' as an alternative term and use quality enhancement when referring to the referendum's goal.

6 A more thorough examination of this point is available from the authors. 
myopically in the sense that they ignore any migration among communities that may result from changing the pattern of river quality across communities in the country. ${ }^{7}$

Let $i$ index individual voters and their locations and let $j=0, \ldots, J$ index a set of discrete distance zones relative to voter $i$. Because a river's quality can be different at different points along its flow, we define segments for each river and frame our analysis in terms of quality in these segments. Assume the utility voter $i$ enjoys from a given river segment, $k$, depends on the distance zone in which the segment is located. River segment $k$ is defined to be in distance zone $j$ relative to voter $i$ if $d_{i k} \in\left[\delta_{j}, \delta_{j+1}\right)$, where $d_{i k}$ is the distance from voter $i$ to river segment $k$ and the $\delta_{j}$ are discrete distances indexed in increasing order. We express utility as follows:

$$
U_{i}=U\left(\mathbf{q}_{\mathbf{i}}, \mathbf{x}_{\mathbf{i}}, Z_{i}, \phi_{i}\right) \text {, }
$$

where $\mathbf{q}_{\mathbf{i}} \equiv\left\{q_{i 1}, q_{i 2}, \ldots, q_{i J}\right\}, \mathbf{x}_{\mathbf{i}} \equiv\left\{x_{i 1}, x_{i 2}, \ldots, x_{i J}\right\}$ and $q_{i j}$ and $x_{i j}$ are measures of the quality and abundance of rivers in distance zone $j$ relative to voter $i$. $Z_{i}$ is $i$ 's consumption of a numeraire private good and $\phi_{i}$ is a preference parameter. Utility is assumed to be increasing in $Z_{i}$, but we make no assumptions on the way in which $q_{i j}$ and $x_{i j}$ enter.

We examine a referendum that proposed to improve river quality and indicate the change $i$ anticipated as a shift from $\mathbf{q}_{\mathbf{i}}^{\mathbf{0}}$ to $\mathbf{q}_{\mathbf{i}}^{\mathbf{0}}+\Delta \mathbf{q}_{\mathbf{i}}$. The minimum expenditure required for $i$ to attain utility level $U_{i}$ given existing river quality at different distances is written

$$
e_{i}=e\left(\mathbf{q}_{\mathbf{i}}, \mathbf{x}_{\mathbf{i}}, U_{i}, \phi_{i}\right) \text {. }
$$

Voter $i$ 's constant utility willingness to pay for the proposed change is given by

$$
\begin{aligned}
W_{i} & =e\left(\mathbf{q}_{\mathbf{i}}^{\mathbf{0}}, \mathbf{x}_{\mathbf{i}}, U_{i}, \phi_{i}\right)-e\left(\mathbf{q}_{i}^{0}+\Delta \mathbf{q}_{\mathbf{i}}, \mathbf{x}_{\mathbf{i}}, U_{i}, \phi_{i}\right) \\
& =-\int_{C} \frac{\partial e(\cdot)}{\partial q_{i 1}} d q_{i 1}+\frac{\partial e(\cdot)}{\partial q_{i 2}} d q_{i 2}+\cdots+\frac{\partial e(\cdot)}{\partial q_{i J}} d q_{i J},
\end{aligned}
$$

where the integral in the second line is taken over a sectionally smooth path, $C$, from $\mathbf{q}_{\mathbf{i}}^{\mathbf{0}}$ to $\mathbf{q}_{\mathbf{i}}^{\mathbf{0}}+\Delta \mathbf{q}_{\mathbf{i}}{ }^{8}$. If river quality in only a single zone changes, willingness to pay is the area under $i$ 's constant utility marginal willingness to pay for quality in that zone, between the pre- and post-policy quality levels. If quality in several zones changes, willingness to pay can be interpreted as a sequential sum of such integrals for individual zones taken in any order. With the policy's benefit expressed in this fashion, intuition suggests that lower levels of initial river quality and greater expected degrees of quality enhancement will both be associated with votes in favour of the referendum. If public good benefits have a local component in the sense described earlier, then (other things equal) yes votes should be more strongly associated with river enhancements $\left(d q_{i j}\right)$ at locations near the voter than those located farther

\footnotetext{
${ }^{7}$ Epple et al. (2001) examine this myopic voter specification as well as an alternative, more sophisticated specification in which voters take public good policies (and resident utilities) in other jurisdictions as given and anticipate migration in response to changes in their own jurisdiction's public good choices. They find evidence supporting the latter view for provision of local public education. While acknowledging the growing evidence on local public good-induced migration and sorting, we defend our simplifying assumption with two arguments: (i) the policy change we study applied uniformly to all of the communities we examine (although its impact on river quality was expected to differ among communities) and (ii) the utility shifts, and hence attractions to migration, likely to result from the policy we study are arguably small in comparison to the utility differentials that arise in the contexts where such sorting has been observed empirically. We comment further on the likely extent of migration induced by this referendum in the next section.

8 This is from the fundamental theorem of the calculus for vector valued functions; see Taylor (1955), p. 471, ff.
} 
away. In principle, the spatial (distance) extent of such local benefits can be identified as the distance at which this association disappears. We cannot test for the presence or strength of economy-wide public good benefits from river enhancement, since by definition such effects would not vary in our sample.

Person $i$ will vote yes on the proposed policy if

$$
N_{i} \equiv W_{i}-\Delta T_{i} \geq 0
$$

where $\Delta T_{i}$ is $i$ 's tax liability. For simplicity we assume indifferent voters vote yes. Although tax liabilities are not observed directly, the revenue source is known to be an income tax. We approximate the tax linearly as $T_{i}=\tau_{0}+\tau_{1} I_{i}^{d}$, where $I_{i}^{d}$ is disposable income. ${ }^{9}$ We assume the project's financing comes from an increase in the marginal tax rate $\tau_{1}$, which implies $\Delta T_{i}=\Delta \tau_{1} I_{i}^{d}$. The $\Delta \mathbf{q}_{\mathbf{i}}$ terms in $W_{i}$ are not observed either, but the greatest enhancements were expected to occur on the most degraded river segments. This expectation is incorporated as follows: $\Delta q_{i j}=\lambda\left(q^{*}-q_{i j}^{0}\right) \forall i, j$, where $\lambda \in[0,1]$. That is, we assume voters expected all rivers to be improved toward a common quality target, $q^{*}$, with the degree of improvement proportional to the initial quality gap.

The hypotheses tested shortly are largely motivated by prior expectations about the shape of the willingness to pay function $W\left(\mathbf{q}_{\mathbf{i}}^{\mathbf{0}}, \Delta \mathbf{q}_{\mathbf{i}}, \mathbf{x}_{\mathbf{i}}, U_{i}, \phi_{i}\right)$. First, $W$ is expected to be decreasing in initial river quality at each distance zone, due to diminishing marginal willingness to pay. Second, willingness to pay is expected to be increasing in the components of $\Delta \mathbf{q}_{\mathbf{i}}$, the expected improvement in various zones; given the expectation that quality increases would be smaller for higher quality river zones, this reinforces the expectation that willingness to pay will be lower when initial river quality is high. Third, the role of river abundance in willingness to pay could in principle be complex. Intuitively, we expect greater willingness to pay for quality enhancement where rivers are abundant, $\partial W / \partial x_{i}>0$. Quality and abundance may also interact in voter preferences. If ex ante quality is high, we expect abundance to have little effect on willingness to pay for quality enhancement because any quality improvement will be minimal. If ex ante river quality is low, we expect the abundance of rivers nearby to have a strong effect on willingness to pay for quality enhancement because the change in quality is large. This translates into an expectation that $\partial^{2} W_{i} / \partial q_{i j}^{0} \partial x_{i j}<0$. We test these empirical propositions by allowing river abundance to enter the willingness to pay function additively and interacted with quality. ${ }^{10}$

Making appropriate substitutions for $\Delta \mathbf{q}_{\mathbf{i}}$ and $\Delta T_{i}$, $i$ 's net-of-tax willingness to pay for river enhancement can be written:

$$
N_{i}=N\left(\mathbf{q}_{\mathbf{i}}^{\mathbf{0}}, \mathbf{x}_{\mathbf{i}}, I_{i}^{d}, \phi_{i}\right) .
$$

We have replaced $U_{i}$ by $I_{i}^{d}$ for empirical purposes because utility is monotonic in disposable income. Notice that $I_{i}^{d}$ could enter positively or negatively, depending on whether marginal benefits progress more or less rapidly with income than tax liabilities.

To move from a criterion for the individual voting decision, which we do not observe, to the voting proportion in a community, which we do observe, we treat $N_{i}$ as a random variable with fixed variance and a mean that depends on the community's mean attributes, $I_{m}^{d}$ and $\phi_{m}$, where the index $m$ indicates the community to which $i$ belongs:

$$
N_{i}=N\left(\mathbf{q}_{m}^{\mathbf{0}}, \mathbf{x}_{m}, I_{m}^{d}, \phi_{m}\right)+\varepsilon_{i} .
$$

9 If the tax is linear in before-tax income it can also be expressed as a linear function of disposable income, which simplifies the notation.

10 We specify that any preference interaction between river quality and river abundance is confined to the same distance zone. 
Recall that initial river quality and river abundance are identical for all individuals in a given community. The error term $\varepsilon_{i}$ is assumed to be logistically distributed with $E\left(\varepsilon_{i}\right)=0$ and fixed variance. The probability of observing a yes vote in community $m$ is

$$
\operatorname{Pr}(\text { yes })=F\left[N\left(\mathbf{q}_{m}^{\mathbf{0}}, \mathbf{x}_{m}, I_{m}^{d}, \phi_{m}\right)\right]
$$

where $F$ is the logistic cdf.

To summarize, Eq. 7 implies that the probability of observing a yes vote in a given community depends on the community's average disposable income, on preference attributes and on pre-policy levels of river quality and river abundance in various distance zones. A finding that this probability varies negatively with initial river quality would be consistent with the hypothesis that there is a local public good component to preferences for river quality. This conclusion would be strengthened if the correlations become weaker with distance from the voter, and in this case the rate of decline would indicate the rate at which local public good benefits diminish with distance. Clearly, such findings would tell us nothing about the presence or absence of economy-wide public good benefits, however, since such benefits would be equally available at all distances and would not vary in our sample. The role of river abundance in voter preferences is addressed by considering specifications that include river abundance in different distance zones as discussed earlier.

\section{Empirical Analysis}

\subsection{The River Restoration Initiative in the Swiss Canton of Bern}

In Switzerland as in other parts of the world (e.g. Bernhardt et al. 2005) many rivers have been regulated over the past decades to gain agricultural land and to prevent flooding. Regulation often occurred in ways that decreased perceived aesthetic and recreational value. Such regulated rivers typically follow a straight line over large stretches, steep banks prevent safe and comfortable access to the water, natural riparian vegetation-which can also serve as a buffer zone against agricultural runoff-was often removed. The resulting homogenous river beds provide poor habitat for fish, which is reflected in a substantial decrease of fish populations over the past decades. ${ }^{11}$ Rather in contrast to the situation in many parts of the US, recreational anglers are only a very small fraction of the population, and the benefits typically associated with river restoration are mainly enhanced landscape quality for local and regional recreation such as walking, jogging or weekend picnics and perceived benefits for wildlife and plants more in general.

In November 1997 the citizens of the Swiss canton of Bern were called to vote on a proposal to establish a cantonal fund for river restoration. ${ }^{12}$ The objective was to restore near-natural river environments (beds and embankments) with native flora and fauna and enhanced aesthetic and recreational value. The initiative demanded that $10 \%$ of the cantonal revenues from water licences, about 3 million SFR per year, be allocated to a fund for river restoration projects in the canton of Bern. The initiative explicitly stated that water fees would not be increased. This fact was also highlighted in the official voter information. Nevertheless, it was

11 Since the early 1980's, the reported trout catch by the roughly 240,000 Swiss anglers has decreased by $60 \%$. Over the same period, the ratio of successful angling trips declined from 78 to $24 \%$, while the trip duration remained the same (Burkhardt-Holm et al. 2005).

12 Schläpfer and Witzig (2006) provide a descriptive empirical analysis of voting results and an extended discussion of the politics leading up to the vote. 
clear that the increase of expenditures for river restoration was an additional expenditure and would therefore have to be balanced by a corresponding increase of the revenues generated through direct taxes on income. The total percentage of yes votes among valid votes was $54.1 \%$. The popular initiative thus prevailed in the vote (Canton of Bern 1997). The voter turnout was $21.1 \%$ which is low but not unusual for a cantonal referendum of relatively minor importance. As there were four items on the ballot, the turnout was not specific to the river restoration issue.

Based on articles published in the local newspaper Berner Zeitung, the opponents did not openly question the need for river restoration but argued that the proposed fund would restrict the budgetary authority of the cantonal parliament and executive in financially difficult times. Proponents were conservation organizations, the cantonal and local anglers' associations and representatives of the construction industry.

\subsection{Definition of Variables}

The voting data we examine are aggregate vote proportions in 366 municipalities of the canton of Bern, reported in the canton's voting protocols (Canton of Bern 1997). These municipalities, the smallest units of local government in Switzerland, vary in population from less than 100 to over 100,000 (City of Bern.)

Information describing the eco-morphological status of the rivers in the study area at the time of the referendum was available from a detailed geo-referenced dataset of the Water and Soil Protection Laboratory of the Canton of Bern (WSPL 2003). This dataset describes the status of each river segment, which was field-recorded following procedures defined by the Federal Office of Environment (FOEFL 1999). The dataset also contains a variable "naturalness" ranging from 1 (for underground river channel) to 5 (for "natural or near-natural status"), which we use as an indicator of quality. Naturalness is defined based on a scoring of several eco-morphological attributes, including variability of river width, extent and type of bed stabilization, extent and type of embankment stabilization, width of riparian zone and vegetation cover. The attribute data are linked to a digital vector map of the rivers and the vector dataset of the rivers was linked with a vector map containing municipal boundaries and town centers (Swisstopo 1999). A comprehensive documentation of the dataset is available in WSPL (2003) and FOEFL (1999). Variables $q_{i j}$ for the weighted mean naturalness and $x_{i j}$ for the density of river segments (in meters of length per square km of area) within a given distance band $j$ from the municipal centers (and situated within the canton of Bern) were derived using standard tools in ArcGIS 9.0. Our empirical analysis focuses on these variables for the distance bands $0-5 \mathrm{~km}, 0-2 \mathrm{~km}$ and $2-5 \mathrm{~km}$. As indicated earlier we also examine the sensitivity of our results to alternative measures of river abundance, $x_{i j}$.

Mean income per taxpayer for municipalities was computed from the total of reported net incomes in the tax period 1997/1998 and the number of taxpayers ("normal cases and special cases with a direct federal tax burden") as reported in the federal tax administration's publication for the tax period 1999/2000 (FTA 2004).

We examined several additional explanatory variables to account for possible variations in voter preferences linked to local socioeconomic, cultural and hydrological factors. The rationale for each of these is explained as results are presented. Population density in the voting districts (municipalities) was derived from the 1990 federal census data (Federal Office of Statistics 2006) and land surface data from the Canton of Bern Office for Municipalities and 
Table 1 Variable definitions and descriptive statistics

\begin{tabular}{|c|c|c|c|c|c|c|}
\hline Name & Definition & $N$ & Mean & SD & Min & Max \\
\hline Yes & Proportion yes votes & 366 & 0.5413 & 0.074 & 0 & 0.87 \\
\hline Logit(Yes) & $\operatorname{Ln}($ Yes/1 - Yes $)$ & 366 & 0.2075 & 0.3127 & $-^{\mathrm{a}}$ & 2.04 \\
\hline \multicolumn{7}{|c|}{ River quality (naturalness) } \\
\hline$q_{0-5}$ & Mean naturalness in $0-5 \mathrm{~km}$. band & 366 & 3.05 & 0.4655 & 2.113 & 4.87 \\
\hline$q_{0-2}$ & Mean naturalness in $0-2 \mathrm{~km}$. band & 365 & 2.65 & 0.8088 & 1.32 & 4.96 \\
\hline$q_{2-5}$ & Mean naturalness in $2-5 \mathrm{~km}$. band & 363 & 3.12 & 0.4799 & 2.14 & 5.00 \\
\hline \multicolumn{7}{|c|}{ River abundance } \\
\hline$x_{0-5}$ & River meters/sq. km., in $0-5 \mathrm{~km}$. zone & 366 & 1121 & 419.5 & 136.2 & 2651.1 \\
\hline$x_{0-2}$ & River meters/sq. km., in $0-2 \mathrm{~km}$. zone & 365 & 1199 & 597.1 & 31.4 & 3592.3 \\
\hline$x_{2-5}$ & River meters/sq. km., in 2-5 km. zone & 364 & 1109.4 & 428.5 & 20.5 & 2634.6 \\
\hline$I_{i}^{d}$ & Mean income (1997, in 1000 SFR) & 366 & 58.18 & 11.29 & 32.34 & 95.06 \\
\hline Density & Population density (pop./hectare) & 366 & 11.00 & 10.60 & 0.0186 & 48.08 \\
\hline Constr. Empl. & Construction employment/ pop. (1990) & 366 & 0.0420 & 0.012 & 0 & 0.118 \\
\hline Flood damage & History of flooding (dummy variable) & 366 & 0.4757 & 0.500 & 0 & 1 \\
\hline Owner Occ. & \% Owner occupied, 1997 & 366 & 37.48 & 17.82 & 10.63 & 83.39 \\
\hline \multicolumn{7}{|c|}{ Dummies for predominant language } \\
\hline French & & 366 & 0.0501 & 0.218 & 0 & 1 \\
\hline German & & 366 & 0.9091 & 0.288 & 0 & 1 \\
\hline \multicolumn{7}{|c|}{ Dummies for geophysical region } \\
\hline Jura & & 366 & 0.1087 & 0.312 & 0 & 1 \\
\hline Prealps & & 366 & 0.1363 & 0.344 & 0 & 1 \\
\hline Alps & & 366 & 0.0740 & 0.262 & 0 & 1 \\
\hline
\end{tabular}

Observations are weighted by the total vote in each municipality

a The community that reported all 'yes' votes was dropped from logit regressions

Spatial Planning (OMSP 2002). The percentage of homes that are owner occupied and the proportion of the population employed in the construction sector were provided by the Federal Office of Statistics. ${ }^{13}$ Language dummies (for Germanic, French and mixed language and cultural background) and region dummies for Jura, Prealps and Alps (for four main geographic regions with Swiss Plateau as the reference) are based on data from the Office of Municipalities and Spatial Planning, Canton of Bern (OMSP 2002). A dummy variable for the occurrence of water related damage by floods and landslides was coded based on the flood and landslide database of the Federal Research Institute WSL, Birmensdorf (Hegg et al. 2000). This variable indicates whether a municipality had been a "main affected municipality" of a flood or landslide at least once during the 10-year period prior to the referendum. Finally, district dummies were coded for the twenty-six administrative districts of the canton of Bern. Brief variable definitions and descriptive statistics are presented in Table 1.

For 11 small municipalities, vote totals were reported only for groups of communities, so votes cast could not be spatially related to river attributes precisely. A similar problem arises for a few 'fragmented' municipalities comprised of non-contiguous land areas, each

13 The percent owner occupied in 1997 was estimated by linear interpolation from data on percent owner occupied in 1990 and 2000. 
with their own center. We chose to drop those voting districts, yielding a dataset with 366 observations.

\subsection{Estimation}

The dependent variable in empirical models is the log odds of the proportion voting yes, Logit(yes). In estimation the observed number of yes votes in a community of $n$ voters is treated as the result of $n$ Bernoulli trials. The observed proportion voting yes then equals the true probability of a yes vote plus a sampling error. This leads to a well-known minimum chisquared estimator, which is implemented by a two-step weighted least squares procedure. ${ }^{14}$ A desirable feature of this estimator is that it weights observations by the total vote, therefore assigning greater weight to larger communities. ${ }^{15}$ To achieve the same end, the summary statistics and simple correlations reported below are weighted by the municipality's total vote.

Voters in each community are treated as if they all reside at the community's center. Average river quality and river abundance are measured in a set of circular zones around each community's center. These zones are small, never exceeding a $5 \mathrm{~km}$. radius. Because the largest concentric zone is very small relative to the entire country, river quality and abundance in the rest of the country (outside the largest concentric zone examined) are treated as identical for all communities and are absorbed in the constant term. A finding that the coefficients of river quality are all zero would imply that voters receive no specific benefit from having river enhancement occur locally. If they care about river quality at all, they perceive it as a nationwide public good. Alternatively, a finding that the local quality coefficients are negative and diminish with distance would indicate that river quality is a local public good to some extent. In either case the nationwide average quality term is part of the constant and its coefficient cannot be identified.

Estimation is based on the following empirical model:

$$
\operatorname{Logit}(\text { yes })=\mathbf{q}_{m}^{\mathbf{0}} \boldsymbol{\beta}+\mathbf{x}_{m} \boldsymbol{\gamma}+\mathbf{q}_{m}^{\mathbf{0}} \mathbf{x}_{m} \boldsymbol{\delta}+I_{m}^{d} \theta+\mathbf{Z}_{\mathbf{m}} \boldsymbol{\psi}+\phi_{m}+\varepsilon_{m},
$$

where $\beta, \gamma, \delta$ and $\psi$ are column vectors of coefficients and $\theta$ is a scalar. In practice we focus on specifications that include only 1 or 2 local distance zones and interactions between river quality and abundance within a given zone. ${ }^{16}$ The reasoning in Sect. 3 leads us to expect that the cross partial derivative of willingness to pay with respect to quality and abundance is negative. We allow for this with the quality $\times$ abundance interaction term. We are aware that the responsiveness of preferences to the quantity, or scope, of environmental amenities has been the subject of intense debate in the environmental economics literature. ${ }^{17}$ Also, the

\footnotetext{
14 Greene (2008).

15 This allows us to interpret our estimates as pertaining to a typical voter rather than a typical community of unstated size.

16 It would be advantageous to have variables for river quality in additional concentric zones around each city center, to test for the presence of a local public good component at greater distances. If these omitted variables are uncorrelated with the quality variables we do include, their exlusion will not bias our estimates of local river quality effects. If there is a positive correlation between quality at the distances we observe and quality at greater distances, and if quality at greater distance zones also has a local component, then our estimated coefficients will be biased downward. In this case our estimated coefficients will partly reflect the effect on votes of quality at the unobserved greater distances. If the local quality coefficients were significant and negative in this case, the presence of a local public good component would still be supported, but the distance at which it occurs would not be correctly identified.
}

17 For example, see Smith and Osborne (1996) and papers cited therein. 
theoretical literature on free-riding in public good provision has examined the possibility that the public good 'quantity' that matters to individuals may not simply be the sum of amounts provided separately. ${ }^{18}$ For these reasons we examine the sensitivity of our results to alternative measures of 'river quantity' (abundance).

We include an extensive vector of community characteristics described earlier (regional dummies, voting district dummies, language dummies, history of prior flood damage, etc.) to control for differences in tastes, but tastes may vary systematically across communities in ways we do not observe. This would be most troublesome if the unobserved taste factor is correlated with variables of interest, in which case the corresponding coefficient estimates will be biased and inconsistent. One possibility is that Tiebout-like sorting caused voters with particularly strong preferences for river naturalness to reside in communities where ex ante river naturalness is high. In this case the unobserved taste variable $\phi_{m}$ would be positively correlated with yes votes and also positively correlated with initial river quality, $\mathbf{q}_{\mathbf{m}}^{\mathbf{0}}$, resulting in an upward bias in $\beta$, which we expect to be negative. If sorting took this particular form, our estimates will be biased in favour of finding no local public good component to river quality enhancement, which is our natural null hypothesis. While this direction of bias seems most plausible to us, we acknowledge that residents may sort on a variety of attributes and, as a consequence, the direction of bias cannot be guaranteed. ${ }^{19}$

While recognizing that sorting could lead to bias, we note that the situation we study does not resemble the setting in which sorting typically has been observed-metropolitan areas in the US and elsewhere, in which communities individually decide on public education and other public goods (Epple and Sieg 1999; Epple et al. 2001; Schmidheiny 2006; Banzhaf and Walsh 2008). The basis for Tiebout sorting within a largely rural Swiss canton is arguably weaker than it is among districts or neighborhoods of metropolitan areas. School quality, which is a major reason for sorting in the US, is relatively homogeneous among the communities we examine as teacher wages and other factors determining school quality are set by the canton. In addition, responsibilities for environmental protection and natural and historical heritage conservation reside with the canton rather than individual communities.

We begin by examining voting responses to variations in local river quality and report results from the simplest specification our model would support. The basic model is then extended to allow for two distance zones, for different patterns of response in different voting districts and for different responses in large versus small communities.

\subsection{Results}

The descriptive statistics in Table 1 indicate wide variation across communities in both river quality and river abundance in all distance zones. The variables we include as controls also vary widely across the sample.

\footnotetext{
18 See Hirshleifer (1983) and Cornes (1993).

19 For example, suppose older voters systematically prefer natural rivers, but older voters also prefer to live in urban locations where rivers tend to be controlled (non-natural). 'Age' belongs in the voting model, but is unobserved so it cannot be controlled; sorting on a preference for urban living causes age to be correlated with ex ante river quality. In this case part of the estimated correlation between yes votes and ex ante river quality will reflect age-related sorting and the effect of age on voter preference; the coefficient of primary interest, $\beta$, will be biased away from zero. The locational equilibrium model of Epple and Sieg (1999) emphasizes that residents may stratify across communities on the basis of more than one variable (income and public good preference in their analysis.) Bayer et al. (2007) provides evidence on the magnitude of bias that can arise from unobserved heterogeneity with regard to willingness to pay for school quality.
} 
Table 2 Simple correlations

\begin{tabular}{|c|c|c|c|c|c|}
\hline Variable & Yes & Logit(Yes) & $q_{0-5}$ & $q_{0-2}$ & $q_{2-5}$ \\
\hline \multicolumn{6}{|c|}{ River quality (naturalness) } \\
\hline$q_{0-5}$ & $-0.4395^{*}$ & $-0.4331^{*}$ & & & \\
\hline$q_{0-2}$ & $-0.4511 *$ & $-0.4415^{*}$ & $0.7270^{*}$ & & \\
\hline$q_{2-5}$ & $-0.4148 *$ & $-0.4095^{*}$ & $0.9685^{*}$ & $0.5730 *$ & \\
\hline \multicolumn{6}{|c|}{ River abundance } \\
\hline$x_{0-5}$ & -0.0341 & -0.0352 & 0.0840 & $0.1618 *$ & 0.0475 \\
\hline$x_{0-2}$ & $-0.2730^{*}$ & $-0.2696^{*}$ & $0.2764^{*}$ & $0.3786^{*}$ & $0.2558^{*}$ \\
\hline$x_{2-5}$ & 0.0338 & 0.0316 & 0.0248 & 0.0819 & -0.0122 \\
\hline
\end{tabular}

* Significant at $1 \%$. Observations are weighted by total vote

Table 2 reports simple correlations for the variables of primary interest, the proportion voting yes, river quality and river abundance in various distance bands. There is a significant, negative correlation between yes votes and quality in all distance zones, which agrees with the local public good hypothesis. For small distance zones within a $2 \mathrm{~km}$ radius of municipal centers river quality is highly correlated across zones, which makes it difficult to resolve the separate effects of quality in different zones. As a consequence we emphasize results only for a single aggregated zone, $0-5 \mathrm{~km}$, or for two zones, $0-2 \mathrm{~km}$ and 2-5 km. No consistent pattern is evident for correlations between yes votes and river abundance. The only significant correlations are for the $0-2 \mathrm{~km}$ band, but their negative sign indicates weaker support for the referendum in communities where rivers are abundant, contrary to expectations. The link between support and river abundance is examined in more detail shortly.

Our model implies that local river quality, river abundance and income all belong in the specification. We also consider a set of conditioning variables to capture variations in tastes or local economic or environmental conditions. Homeowners may perceive their stake in river restoration to be different than renters for at least two reasons. First, river quality benefits may be capitalized into housing prices; this would raise the price of housing services and would enhance the wealth of homeowners, but not renters. Second, renters typically are more transient than owners, so proximity to a degraded river at the time votes are cast need not imply any long term benefit. We include percent owner occupied for these reasons. Voters may derive different amenities from rivers in urban versus rural settings, which motivates us to include population density as a determinant of voter support. Population density would also belong in the model if congestion figures significantly in the enjoyment of rivers, although in the context of Bern this seems unlikely. While we do include population density, we note that it is highly correlated with percent owner occupied (corr. $=-.88$ ), so the effects of these variables may be difficult to separate.

Voter support may well be linked to variations in the physical environment, which we represent with dummy variables for three of the four geographic regions in the canton, Jura, Alps and Prealps. Language differences reflect cultural factors related to preferences, and we capture these with dummy variables for regions in which French versus German predominate (regions in which the two are found together is the default). The proposed river enhancement was expected to cause construction activity and was supported by construction industry groups; we allow for this effect by including employment in the construction industry relative to population. Because a past history of flooding may cause a community to regard the local river as a force to be tamed rather than an object of preservation, we include the dummy 
Table 3 Testing for the effect of local naturalness

\begin{tabular}{|c|c|c|c|c|}
\hline Variables* & (1) & (2) & (3) & (4) \\
\hline$q_{0-5}$ & 0.1550 (1.69) & - & $0.2855(2.87)$ & - \\
\hline$x_{0-5}$ & $8.62 \mathrm{e}-04(3.55)$ & - & $0.0013(4.12)$ & - \\
\hline$q_{0-5} \times x_{0-5}$ & $-2.77 \mathrm{e}-04(-3.70)$ & - & $-4.18 \mathrm{e}-04(-4.62)$ & - \\
\hline$q_{0-2}$ & - & $0.1362(2.76)$ & - & $0.1032(1.99)$ \\
\hline$x_{0-2}$ & - & $4.09 \mathrm{e} 04(3.01)$ & - & $3.80 \mathrm{e}-04(2.70)$ \\
\hline$q_{0-2} \times x_{0-2}$ & - & $-1.68 \mathrm{e}-04(-3.68)$ & - & $-1.47 \mathrm{e}-04(-3.19)$ \\
\hline$q_{2-5}$ & - & $-0.0194(-0.24)$ & - & $0.1194(1.43)$ \\
\hline$x_{2-5}$ & - & $1.82 \mathrm{e}-04(0.72)$ & - & $6.55 \mathrm{e}-04(2.15)$ \\
\hline$q_{2-5} \times x_{2-5}$ & - & $-3.88 \mathrm{e}-05(-0.50)$ & - & $-1.95 \mathrm{e}-04(-2.19)$ \\
\hline $\begin{array}{l}I_{i}^{d}(\text { mean } \\
\text { income })\end{array}$ & $-2.65 \mathrm{e}-04(-0.20)$ & $3.65 \mathrm{e}-04(0.25)$ & $-8.94 \mathrm{e}-04(-0.64)$ & $1.28 \mathrm{e}-04(0.08)$ \\
\hline Density & $0.0019(0.67)$ & $0.0063(0.22)$ & $-0.0043(-1.41)$ & $-0.0037(-1.20)$ \\
\hline French lang. & $-0.4928(-5.58)$ & $-0.4856(-5.50)$ & $0.2560(0.27)$ & $-0.0062(-0.01)$ \\
\hline German lang. & $-0.5206(-4.55)$ & $-0.5262(-4.33)$ & $-0.6552(-5.73)$ & $-0.7271(-5.55)$ \\
\hline Constr. Empl. & $-2.5183(-1.74)$ & $-2.3122(-1.60)$ & $-2.7696(-1.99)$ & $-2.9601(-2.13)$ \\
\hline Flood damage & $0.0297(1.07)$ & $0.0070(0.25)$ & $0.0248(0.83)$ & $0.0018(-0.06)$ \\
\hline $\begin{array}{l}\text { Owner } \\
\text { Occupied }\end{array}$ & $-0.0049(-3.16)$ & $-0.0051(-3.20)$ & $-0.0072(-4.65)$ & $-0.0067(-4.15)$ \\
\hline $\begin{array}{l}\text { Regional } \\
\text { dummies }\end{array}$ & Yes & Yes & Yes & Yes \\
\hline $\begin{array}{l}\text { District } \\
\text { dummies }\end{array}$ & No & No & Yes & Yes \\
\hline$N$ & 365 & 361 & 365 & 361 \\
\hline Adj. $R^{2}$ & 0.40 & 0.42 & 0.51 & 0.53 \\
\hline
\end{tabular}

Notes: $t$-Statistics in parentheses. Estimation is by GLS; see Greene (2008). In all 4 models the quality, quantity and interaction coefficients are jointly significant at 0.00001

$* q_{0-5}$ and $x_{0-5}$ are, respectively, mean naturalness and river meters in the $0-5 \mathrm{~km}$. band; other $q$ and $x$ variables are defined similarly

variable for a history of flood damage. Finally, spatial heterogeneity that we do not observe may affect support in ways not captured by our controls. We account for this possibility by including dummy variables for 25 of the 26 voting districts in the canton. We find the regional and district dummies to be significant in all specifications but do not report these coefficients to simplify the tables.

Table 3 presents 4 variations on our basic specification: models with vs. without district dummies and models with 1 versus 2 distance zones. ${ }^{20}$ The river quality and quantity variables are jointly significant at $.01 \%$ in all 4 specifications. In keeping with expectations the quality $\times$ abundance interaction terms are negative in all cases and 5 out of 6 estimates are highly significant. The broad interpretation of this result is that the effect of local river

\footnotetext{
20 Apart from the inclusion of additional control variables, this "starting point" specification (model 1 in Table 3) corresponds to the "final" model in Schläpfer and Witzig (2006, Table 4, last column). The pattern of significant (corresponding) parameters is essentially the same, except for population density which, as mentioned above, is highly correlated with the additional control variable 'owner occupied'.
} 
Table 4 Partial derivatives of Logit(Yes) with respect to $q$ and $x$

\begin{tabular}{lllll}
\hline Variables* & $(1)$ & $(2)$ & $(3)$ & $(4)$ \\
\hline \multicolumn{2}{l}{ River naturalness } & & & \\
$q_{0-5}$ & $-0.1518(-3.46)$ & - & $-0.1779(-3.19)$ & - \\
$q_{0-2}$ & - & $-0.0935(-2.75)$ & - & $-0.0983(-2.88)$ \\
$q_{2}-5$ & - & $-0.0607(-1.21)$ & - & $-0.0877(-1.53)$ \\
River abundance & & & \\
$x_{0-5}$ & $-3.12 \mathrm{e}-05(-0.81)$ & - & $-6.87 \mathrm{e}-5(-1.17)$ & - \\
$x_{0-2}$ & - & $-1.11 \mathrm{e}-04(-3.62)$ & - & $-7.61 \mathrm{e}-05(-2.31)$ \\
$x_{2}-5$ & - & $5.53 \mathrm{e}-05(1.35)$ & - & $1.94 \mathrm{e}-05(0.33)$
\end{tabular}

Notes: $t$-Statistics in parentheses. Columns 1-4 show derivatives for models in the corresponding columns of Table 3. Derivatives with respect to meters in the two distance bands from col. 4 estimates are significantly different. We cannot reject the hypothesis of equality in different distance bands for the other partial derivatives with respect to quality and quantity estimates

$* q_{0-5}$ and $x_{0-5}$ are, respectively, mean naturalness and river meters in the $0-5 \mathrm{~km}$. band; other $q$ and $x$ variables are defined similarly

quality depends on the local abundance of rivers (and vice versa). Because the interactions are generally significant, the effects of quality alone or quantity alone on yes votes must be expressed as partial derivatives. Estimates and hypothesis tests for these partial derivatives are presented shortly.

Income is insignificant in all 4 cases and inconsistent in sign, suggesting that tax obligations progress with income at approximately the same rate as willingness to pay. ${ }^{21}$ Yes votes show no consistent correlation with population density. (However, in models that exclude percent owner occupied as a regressor, population density enters with a highly significant, positive coefficient.) The dummies indicating French and German language predominance are significant in the models that exclude district dummies; the variable for French language predominance becomes insignificant when district dummies are included. High construction employment is negatively linked to yes votes, contrary to expectations, and the effect is significant at $10 \%$. While we cannot provide a definite reason, one plausible possibility is that, while some construction groups stood to gain employment from river enhancement projects, others may have feared that a move toward preserving rivers in a natural state would block future construction in areas near rivers. The dummy variables for geographic regions and voting districts are highly significant when included. The dummy variable for prior flood damage is not significant. We did not have a clear expectation that prior flood damage would have a negative effect on yes votes. According to our media analysis, effects on flooding were not an issue in the pre-referendum debate. Moreover, river restoration projects today are typically executed with the additional objective of reducing the risk of flooding. Finally, percent owner occupied is negative and significant in all specifications. Considerations of benefit capitalization and transiency of renters led us to expect the reverse. While controlling for owner occupancy is appropriate on theoretical grounds, isolating the effect turns out to be empirically difficult in the present case. As mentioned above, percent owner occupied turns out to be strongly correlated with population density (and hence the urban-rural

21 Schläpfer and Witzig (2006) found income to be positively associated with yes votes, but the effect was never highly significant and only approached significance $(p \approx .10)$ in 1 of 6 specifications examined. Their specification differed in several respects from the specifications in Table 3. 
gradient) which is well known to be an important determinant in many voting decisions on environmental public goods.

We compute partial derivatives of Logit $(Y e s)$ with respect to quality and abundance in order to consider hypotheses about their partial effects. Recall that a negative partial derivative of Logit(Yes) with respect to local river quality would support the hypothesis that river quality has a local public good component and this conclusion would be strengthened if the partial derivative diminishes in absolute magnitude at greater distances from community centers. The relevant partial derivatives, evaluated at sample means, are shown in the first 3 rows of Table $4{ }^{22}$ The effect of higher river quality is negative and significantly different from zero when a single distance zone is considered (columns 1 and 3) whether or not district dummies are included in estimation, indicating a spatially restricted component of river restoration benefits. ${ }^{23}$ When 2 distance zones are allowed, partial derivatives with respect to quality in each distance zone are both negative and their magnitudes diminish with distance. The outside zone coefficients are not highly significant, however. We cannot reject the hypothesis that the partial derivatives of quality in the 2 distance bands are equal for the estimates in col. 2 or for those in col. 4.

We argued earlier that river naturalness may affect votes differently in urban versus rural settings. This motivated us to include population density as a control and some of this effect may be captured by percent owner occupied. Incorporating such effects with additive terms is appropriate if the difference operates through a simple shift in support regardless of the local naturalness level. A simple additive term will not capture this effect, however, if the value placed on naturalness differs in urban vs. rural settings. In more urbanized settings, the local river may be a focal point of commercial, leisure and tourist activity; in rural areas most of the local rivers may be more integrated into the natural environment. We test for this possibility by amending the model of col. 3 in Table 3 to allow for different responses to river quality and abundance in different size municipalities. We use 'total vote' to define large versus small municipalities, with the dividing line set at 1000. Coefficient estimates are shown in Table 5 and partial derivatives in Table 6. An $F$ test on the coefficients involving DSmall interactions in Table 5 indicates that the response to local river quality is significantly different in small municipalities than in large municipalities. The partial derivatives in Table 6 indicate that local river quality matters more in small municipalities than in large municipalities. Estimating the model with 2 distance bands, interactions, and separate treatments for large versus small communities makes the model more unwieldy, but leads to similar conclusions; yes votes are negatively related to initial river quality and the response is stronger in small municipalities than in large ones. ${ }^{24}$

We observed earlier that the quantity of restoration anticipated in any local area should be greater where rivers are more abundant. This leads us to expect that, if river quality has a local public good component, yes votes will be more prevalent where rivers are extensive. To test this we computed partial derivatives of Logit(Yes) with respect to river abundance

\footnotetext{
22 Using the notation in Eq. 8 the partial derivative of Logit(Yes) with respect to $q_{j}$ is $\beta_{j}+\delta_{j} x_{j}$, where the $j$ subscripts for $\beta$ and $\delta$ refer to the $j$ th elements in the parameter vectors. Point estimates and standard errors for these derivatives were computed as linear functions of the coefficient estimates in Table 3 , using sample means of appropriate $x_{j}$ terms (using the lincom command in STATA). Partial derivatives with respect to quantity, discussed shortly, were computed similarly.

23 Schläpfer and Witzig (2006) based their conclusion on spatially restricted benefits on the coefficient from a model that excludes a quantity $\times$ quality interaction, which is not entirely legitimate in light of the fact that this interaction was statistically significant.

24 These estimates are available on request. Also, the response of yes votes to river quality is not significantly different in the 2 distance bands for large communities; for small communities the difference is only marginally significant.
} 
Table 5 Naturalness effects in large versus small municipalities

Notes: Dummy variables for geographic regions and voting districts are included.

DSmall $=1$ if the total vote is less than 1,000. The variables interacted with DSmall are jointly significant at 0.00005

${ }^{*} q_{0-5}$ and $x_{0-5}$ are, respectively, mean naturalness and river meters in the $0-5 \mathrm{~km}$. band

\begin{tabular}{ll}
\hline Variables* & Coef. \\
\hline$q_{0-5}$ & $0.2203(2.22)$ \\
$q_{0-5} \times \mathrm{DSmall}$ & $-0.0019(-0.07)$ \\
$x_{0-5}$ & $0.0011(3.25)$ \\
$x_{0-5} \times \mathrm{DSmall}$ & $1.61 \mathrm{e}-04(0.92)$ \\
$q_{0-5} \times x_{0-5}$ & $-3.40 \mathrm{e} 0-4(-3.46)$ \\
$q_{0-5} \times x_{0-5} \times \mathrm{DSmall}$ & $-8.93 \mathrm{e}-05(-1.54)$ \\
$I_{i}^{d}($ mean income) & $-0.0012(-0.90)$ \\
Density & $-0.0031(-1.01)$ \\
French lang. & $0.2154(0.24)$ \\
Constr. Empl. & $-2.5249(-1.87)$ \\
Flood damage & $-0.0043(-0.15)$ \\
Owner Occupied & $-0.0049(-3.08)$ \\
$\mathrm{N}$ & 365 \\
Adj. $R^{2}$ & 0.55
\end{tabular}

Table 6 Partial derivatives of Logit(Yes) with respect to $q$ and $x$

\begin{tabular}{lll}
\hline Variables* & Small communities (1) & Large communities (2) \\
\hline$q_{0-5}$ & $-0.2504(-4.44)$ & $-0.1568(-2.25)$ \\
$x_{0-5}$ & $-1.12 \mathrm{e}-05(-1.94)$ & $6.43 \mathrm{e}-05(0.77)$
\end{tabular}

Note: $t$-Statistics in parentheses. The differences in partial derivatives for large vs. small communities are statistically significant at $10 \%$ for river quality and at $1 \%$ for meters

* $q_{0-5}$ and $x_{0-5}$ are, respectively, mean naturalness and river meters in the $0-5 \mathrm{~km}$. band; other $q$ and $x$ variables are defined similarly

and report the estimates (evaluated at sample means) in Tables 4 and 6 . In models with a single distance band (Table 4, col. 1 and 3 and Table 6 col. 1 and 2) the partial derivatives with respect to $x$ are inconsistent in sign and statistically significant in only 1 instance. In models with 2 distance bands the quantity derivatives are significant in 2 (out of 4) cases but are again inconsistent in sign. None of the 8 quantity responses estimated is significant and positive.

Perhaps voters care that some threshold level of local rivers exist to be enhanced, but do not perceive benefits that are linearly related to abundance. We examined this possibility by defining a dummy variable that takes the value 1 if river density in a given zone is greater than $1 \mathrm{~km}$. of length per square $\mathrm{km}$. of area (and 0 otherwise), and using it in place of the abundance variables defined earlier. (With the threshold set at this value, the dummy variable takes the value 1 in approximately one-half of the distance bands in our sample.) Overall, the results changed very little from those reported earlier. For the counterpart of Table 3 (cols. 3 and 4) the new quality $\times$ abundance interaction terms are negative and highly significant in both 1 distance band and 2 distance band models. For the counterpart of Table 4, the partial derivative of yes votes with respect to this new abundance measure is negative and significant for the $0-2 \mathrm{~km}$. distance band, but inconsistent in sign and insignificant in the other two cases. The revised partial derivatives of yes votes with respect to the quality measures are only slightly different than the estimates reported in Table 4. 
Table 7 Voting results in counter factual simulations

\begin{tabular}{lllllll}
\hline & \multicolumn{2}{l}{ Table 3, col. 3 Predicted } & & \multicolumn{2}{l}{ Table 3, col. 4 Predicted } \\
& C-factual & Actual & & C-factual & Actual \\
\hline Popular 'yes' vote, canton-wide (\%) & 46.6 & 54.2 & & 46.2 & 54.2 \\
Number of municipalities approving & 87 & 216 & & 77 & 210 \\
\hline
\end{tabular}

\subsection{Discussion}

Our key findings are two-fold. First, the benefits from canton-wide river restoration have a strong local component. Empirically, voter support is lower when local rivers are relatively pristine. This observation is consistent with the local public good interpretation if one accepts a simple diminishing marginal utility argument and the plausible voter expectation that more pristine rivers faced little possibility of enhancement. The related prediction that the effect of river quality on voter support should diminish with distance away from municipal centers is supported in point estimates for the partial derivatives, but the differences in partial derivatives are not significant. Second, voter support bears no consistent positive relationship to the local abundance of river segments, which we hypothesized is a good indicator of the likely extent of local public good improvement. The following discussion addresses both findings.

On the first point, the results indicate that the local component of benefits is statistically significant but they do not indicate the relative importance of local versus canton-wide benefits. While we clearly cannot estimate the relative size of canton-wide versus local public good benefits, we can investigate whether or not the local component was sufficiently strong to 'matter' in the voting outcome. To shed light on this, we compute predicted yes votes under a counter factual situation where each community's river quality variable takes the value "5". Under the counter factual, each voter's local rivers are pristine ex ante but river conditions elsewhere in the canton are at actual values. Accordingly, the counter factual gives the predicted outcome if voters expected the referendum to have no effect on local river quality but to enhance quality elsewhere. Using the estimates from cols. 3 and 4 in Table 3, we obtain the results shown in Table 7. ${ }^{25}$ Absent local enhancement benefits the referendum would have failed canton-wide, with $45.2-46.6 \%$ voting yes; the predicted yes vote under actual conditions was $54.2 \%$. Further, only 77-87 (out of 366) municipalities would have voted to approve the measure in the counter factual situation, whereas the predicted vote under actual conditions resulted in a majority preferring passage in 210 municipalities.

The results could be used to provide rough empirical guidance for assigning funding responsibilities between municipalities and the canton. Following the logic of fiscal federalism, the findings arguably suggest that a system of matching grants - in which cantonal support is conditioned on a contribution by the local governments-would promote a provision of the public good that is responsive to voter preferences. Regarding further practical implications, the result that the coefficient on income was non-significant in spite of a substantial variation in mean income in the communities (see Table 1) indicates that the marginal benefits of river restoration progress with income about as rapidly as the progressive income tax schedule (cf. model section). In public decisions, these result may usefully

\footnotetext{
25 We compare predicted votes under actual circumstances (observed values for independent variables) to predicted votes under the counter factual situation; we thus hold constant the realization of the error term in the two circumstances. Predicted values for the proportion voting yes for each observation were obtained using the predictnl command in Stata.
} 
complement evidence derived using other approaches such as recreation demand models (e.g. Phaneuf and Smith 2005).

The second point we discuss is the counterintuitive result that voter support for canton-wide river restoration bears no consistent, positive relationship to the local abundance of rivers. This is surprising because, for a given current river quality, the extent of local enhancement that would result from the canton-wide program should clearly be positively related to the abundance of river segments in the voter's local area. One possible explanation could involve a decreasing marginal utility argument. While communities with abundant local rivers receive more of the physical improvements, they may perceive smaller economic benefits from a given amount of quality improvement due to decreasing marginal utility. An alternative explanation for an inconsistent sensitivity to abundance, or quantity, is that voters regard the good offered as "a local environment with high quality rivers" rather than a specific amount of river enhancement. ${ }^{26}$ This might be motivated by a sense of 'stewardship' - a wish to enhance or protect the quality of any rivers found in the local area, regardless of abundance. Similar non-responsiveness to quantity or scope has been reported in CV studies on natural resource damage assessment (Boyle et al. 1994; McFadden 1994). ${ }^{27}$

Another interpretation is based on recent findings from political science. In recent years, political scientists have produced evidence that voters are badly informed about the content of proposed policies. Nevertheless, poorly informed voters, even when facing complex ballot issues, often can make optimizing voting choices by following cues or "short cuts" revealed by the political debate (Lupia 1994; Lupia and Matsusaka 2004). Cues revealed by the identity of groups who support and oppose a given ballot measure can be particularly powerful in this regard. This finding may reconcile the consistent explanatory patterns usually found in the analysis of voting behavior with the frequent "anomalies" in survey-based preference elicitation. If the political scientists' interpretation is correct, economic preferences will consistently reflect the local condition of a public good only at those spatial scales at which an informed public debate has taken place. In the present case, the requirement for voter preferences to consistently reflect river conditions within a radius of $5 \mathrm{~km}$ of municipal centers would be an informed community-level debate. However, according to our media analysis and personal communications, the debate between proponents and opponents of the initiative took place largely at the cantonal level. In this light, it is perhaps not surprising to find that local votes did not consistently reflect the local abundance of rivers, and hence the quantity of enhancement likely to occur locally. ${ }^{28}$ The same reasoning would seem to predict a corresponding insensitivity to quality differences, however, which is contrary to what we observe.

A caveat regards the observational nature of the data. Although we controlled for variables such as income, population density (to account for the urban-rural difference in preferences), owner occupancy and regional heterogeneity, we cannot rule out the possibility that the effect of river quality is due to another correlated variable. Furthermore, we cannot rule out the possibility that some voters interpreted the locally perceived river quality as the canton-wide

\footnotetext{
26 Kolstad (2000, p. 371) suggests this explanation for the anomalous CV results cited next.

27 Rollins and Lyke (1998) argue that insensitivity of existence values to scope can be rationalized if one allows marginal existence values to be diminishing in a set of natural assets being considered for protection. This argument seems not to apply in the present circumstance, however, as the values involved are arguably use values. Rivers in most of the communities examined are a prominent part of the local environment and voters presumably 'visit', or interact with, them regularly. Indeed, the frequency with which an average resident does interact, and the use values enjoyed, should be positively related to the density of local rivers.

28 The voter preferences for the "local component" of the public good may thus be similar in nature to the stated preferences of an isolated survey respondent.
} 
average quality. For those voters, the observed effect of local river quality would then not necessarily imply a local benefit component. ${ }^{29}$ Finally, residents may have sorted themselves based on preferences forex ante river quality, in which case the corresponding coefficients are biased toward zero. If the differences between quality coefficients at different distance bands are also biased toward zero the rate at which benefits decline with distance and the importance of the local public good component would be underestimated. We must acknowledge, however, that the bias could run in the other direction if voters sort on other unobserved attributes.

Further standard caveats concern the assumptions underlying our use of aggregate rather than individual voting data and a relatively low turnout in the vote. The use of aggregate voting data is of greatest concern when relationships between individual-level variables and voting are the main interest. This issue is less prominent in the present analysis because our main hypotheses relate to the role of environmental variables that are measured at the level of the municipalities and are identical for the individuals in a local voter population. Naturally, our results can only shed light on the preferences of those citizens who actually turned out to vote. While it is sometimes claimed that low turnout favours right leaning or conservative candidates and policies, recent evidence from the political science literature suggest that turnout has surprisingly little effect in biasing outcomes in one ideological direction or the other, as highly contentious issues tend to mobilize voters from both sides (e.g. Martinez and Gill 2005). Also, the referendum we examine was on the ballot with three other issues, so the group that turned out to vote presumably included citizens with interests in a range of policies. Regarding the turnout of different socioeconomic groups, the empirical evidence suggests that neither education, nor income, nor social status has any impact on electoral participation in Switzerland (Wernli 2001, p. 64-68; see Kriesi 2007). For directdemocratic votes, it has been shown that educational attainment does contribute to participation but that the effect is rather limited (Mottier 1993, p. 134; see Kriesi 2007).

\section{Conclusions}

For several reasons, referendum voting is a valuable source of preference information about public goods. In contrast to the hypothetical votes in surveys, the relevant geographic extent of the public good improvement and the distribution of costs are clearly and credibly defined. Moreover, the specific proposition has been the subject of political debate in which the voters are exposed to a variety of arguments from both sides. Our findings indicate that canton-wide (or state-wide) referendum voting on public good provision offers a valuable opportunity for analyzing how far the localized benefits of public goods extend, at least qualitatively.

Results on the spatial distribution of benefits can provide a useful starting point for the equitable assignment of financial responsibilities between multiple levels of government in federal systems. A better understanding of the spatial distribution of benefits would allow the costs of improvements to be distributed between local and national governments in ways that reflect this distribution of benefits. If costs were shared in this fashion, our results indicate that local municipalities would be asked to contribute significantly to the financing of river improvements.

Accurate information on the spatial extent of public good amenities could also be useful in assigning policy decisions to specific jurisdictions. If jurisdiction limits and financing

29 This could yield the same pattern we observe because voters in communities where local river quality is low would perceive quality to be low canton wide, and therefore vote in favor even if benefits have no local component. 
responsibilities for such goods are not defined to coincide with the area over which benefits extend, benefits and costs will not be appropriately compared in ordinary collective choice processes. This is true with ordinary voting mechanisms, which do not allow expression of preference intensity. A policy proposal that would pass a straightforward benefit cost test may fail to gain majority approval if its benefits are concentrated in a particular region, while costs are spread across a larger area. Conversely, a policy that would fail a benefit cost test might gain approval if it imposes spatially concentrated costs and generates more broadly dispersed benefits. In principle these problems could be solved by bundling together policies with spatially lumpy benefits or costs in a way that results in positive net benefits for all localities. Such bundling would be complicated in practice, however, and would itself require information on spatial benefit distributions. We make no claim that our estimates provide a sufficient basis for such financing or jurisdictional decisions, but they do illustrate that spatial analysis of referendum voting can in principle be used to address such questions.

Our finding that support for river enhancement is not consistently related to the extent of rivers in the voter's locality is troubling, and raises questions about how heavily one can lean on these results for policy purposes. The possibility that this behavior reflects a stewardship motive is clearly speculative without further evidence; if true the implications for policy and the application of benefit-cost tests would be substantial. Alternatively, the lack of a consistent pattern of scope sensitivity may stem from the limited "spatial resolution" of the (canton-level) pre-referendum debate, which in turn failed to accurately inform voters on the likely spatial pattern of public good improvement. If so, the spatial voting patterns we interpret as evidence on preferences may actually be a consequence of the spatial scale of the political processes that voters relied upon for information to inform their voting choices.

Acknowledgements Without implicating them for any errors, we gratefully acknowledge valuable comments received from several anonymous referees and from Nick Burger, Glenn Harrison, Mark Dickie and seminar participants at the University of Central Florida, the University of California, Santa Barbara, and the University of Zurich. The authors would like to thank representatives of the Swiss Federal Office for Environment and the Water and Soil Protection Laboratory of the Canton of Bern for providing the eco-morphological data. Christoph Hegg and Nadine Hilker of the Federal Research Institute WSL provided the data of their flood damage database. The Federal Office of Statistics provided census data. Personal communications from U. Ochsenbein and M. Zeh of the cantonal Water and Soil Protection Laboratory, H. Aschwanden and R. Estoppey of the Federal Office for Environment, W. Mueller, the director of the Bernese river restoration fund and A. Dettwiler of Property Insurance Bern are gratefully acknowledged. We also thank Thomas Schulz for GIS support and Fabian Waltert for preparing census data.

Open Access This article is distributed under the terms of the Creative Commons Attribution Noncommercial License which permits any noncommercial use, distribution, and reproduction in any medium, provided the original author(s) and source are credited.

\section{References}

Abeles-Allison M, Connor LJ (1990) An analysis of local benefits and costs of Michigan hog operations experiencing environmental conflicts. Agricultural Economics Report No. 536. Department of Agricultural Economics, Michigan State University, East Lansing

Acharya G, Bennett LL (2001) Valuing open space and land-use patterns in urban watersheds. J Real Estate Finance Econ 22(2-3):221-237

Banzhaf HS, Walsh RP (2008) Do people vote with their feet? An empirical test of Tiebout. Am Econ Rev 98(3):63-843

Bayer P, Ferreira F, McMillan R (2007) A unified framework for measuring preferences for schools and neighborhoods. J Polit Econ 115(4):588-638

Bateman IJ, Langford IH (1997) Non-users' willingness to pay for a National Park: an application and critique of the contingent valuation method. Reg Stud 31(6):571-582 
Bateman IJ, Langford IH, Nishikawa N, Lake I (2000) The Axford Debate revisited: a case study illustrating different approaches to aggregation of benefits data. J Environ Plann Manag 43(2):291-302

Bateman IJ, Day BH, Georgiou S, Lake I (2006) the aggregation of environmental benefit values: welfare measures, distance decay and total WTP. Ecol Econ 60:450-460

Berner Zeitung (1997). Various editions. Verlag Berner Zeitung, Bern, Switzerland

Bernhardt ES, Palmer MA, Allan JD et al (2005) Ecology—synthesizing US river restoration efforts. Science 308(5722):636-637

Bowen HR (1943) The interpretation of voting in the allocation of economic resources. Q J Econ 58:27-48

Boyle KJ, Desvousges WH, Johnson FR, Dunford RW, Hudson SP (1994) An investigation of part-whole biases in contingent-valuation studies. J Environ Econ Manag 27(1):64-83

Burkhardt-Holm P, Giger W, Güttinger H, Ochsenbein U, Peter A, Scheurer K, Segner H, Staub E, Suter ME (2005) Where have all the fish gone? The reasons why the fish catches in Swiss rivers are declining. Environ Sci Technol 39:441A-447A

Canton of Bern (1997) Abstimmungsprotokolle der Gemeinden des Kantons Bern bei der kantonalen Volksabstimmung über den Volksvorschlag ,für einen Renaturierungsfonds im Wassernutzungsgesetz vom 23. November 1997" (Voting Protocols)

Cornes R (1993) Dyke maintenance and other stories: some neglected types of public goods. Q J Econ 108(1):259-271

Cornes R, Sandler T (1996) The theory of externalities, public goods and club goods. Cambridge University Press, Cambridge

Deacon R, Shapiro P (1975) Private preference for collective goods revealed through voting on referenda. Am Econ Rev 65(5):943-955

Epple D, Sieg H (1999) Estimating equilibrium models of local jurisdictions. J Polit Econ 107(4):645-681

Epple D, Romer T, Sieg H (2001) Interjurisdictional sorting and majority rule: an empirical analysis. Econometrica 69(6):1437-1465

Federal Office of Statistics (2006) Federal Census data 1990. Statweb, Federal Office of Statistics, Neuchatel, Switzerland

Fischel WA (1979) Determinants of voting on environmental quality: a study of a New Hampshire pulp mill referendum. J Environ Econ Manag 6(2):107-118

FOEFL (1999) Methoden zur Untersuchung und Beurteilung der Fliessgewässer. Vollzug Umwelt: Mitteilungen zum Gewässerschutz, Nr. 26/27. Federal Office for the Environment, Forest, and Landscape, Bern, Switzerland

FTA (2004) Direkte Bundessteuer, Steuerperiode 1999/2000, Natürliche Personen. Federal Tax Administration, Bern (Data provided in the internet; accessed June 2005)

Geoghegan J (2002) The value of open spaces in residential land use. Land Use Policy 19(1):91-98

Geoghegan J, Wainger LA, Bockstael NE (1997) Spatial landscape indices in a hedonic framework: an ecological economics analysis using GIS. Ecol Econ 23(3):251-264

Greene WH (2008) Econometric analysis. 6. Prentice Hall, Englewood Cliffs

Hanley N, Schläpfer F, Spurgeon J (2003) Aggregating the benefits of environmental improvements: distancedecay functions for use and non-use values. J Environ Manag 68(3):297-304

Hegg C, Gerber D, Röthlisberger G (2000) Unwetterschaden-Datenbank der Schweiz. In: International symposium interpraevent. Villach, Austria, Proceedings vol 1, pp 37-48

Herriges JA, Secchi S, Babcock BA (2005) Living with hogs in Iowa: the impact of livestock facilities on rural residential property values. Land Econ 81(4):530-545

Hirshleifer J (1983) From weakest-link to best-shot: the voluntary provision of public goods. Public Choice 41:371-386

Irwin EG (2002) The effects of open space on residential property values. Land Econ 78(4):465-480

Kahn ME, Matsusaka JG (1997) Demand for environmental goods: evidence from voting patterns on California initiatives. J Law Econ 40(1):137-173

Kline J, Wichelns D (1994) Using referendum data to characterize public support for purchasing development rights to farmland. Land Econ 70(2):223-233

Kolstad CD (2000) Environ Econ. Oxford University Press, Oxford

Kotchen MJ, Powers SM (2006) Explaining the appearance and success of voter referenda for open-space conservation. J Environ Econ Manag 52(1):373-390

Kriesi H (2007) The participation in Swiss direct-democratic votes. In: Vreese CHde (ed) The dynamics of referendum campaigns. An international perspective. Palgrave Macmillan, Basingstoke pp 117-141

Loomis JB (2000) Vertically summing public good demand curves: an empirical comparison of economic versus political jurisdictions. Land Econ 76(2):312-321

Lupia A (1994) Shortcuts versus encyclopedias-information and voting- behavior in California insurance reform elections. Am Polit Sci Rev 88(1):63-76 
Lupia A, Matsusaka JG (2004) Direct democracy: new approaches to old questions. Annu Rev Polit Sci 7:463-482

Mahan BL, Polasky S, Adams RM (2000) Valuing urban wetlands: a property price approach. Land Econ 76(1):100-113

McConnell KE (1990) Double counting in hedonic and travel cost models. Land Econ 66(2):121-127

McFadden D (1994) Contingent valuation and social choice. Am J Agric Econ 76(4):689-708

Michaels RG, Smith VK (1990) Market-segmentation and valuing amenities with hedonic models-the case of hazardous-waste sites. J Urban Econ 28(2):223-242

Martinez MD, Gill J (2005) The effects of turnout on partisan outcomes in U.S. presidential elections 19602000. J Polit 67:1248-1274

Mottier V (1993) La structuration sociale de la participation aux votations fédérales. In: Kriesi HP (ed) Citoyenneté et démocratie directe. Seismo, Zurich, pp. 123-144.

Nelson E, Uwasu M, Polasky S (2007) Voting on open space: what explains the appearance and support of municipal-level open space conservation referenda in the United States? Ecol Econ 62(3-4):580-593

Noam EM (1981) The valuation of legal-rights. Q J Econ 96(3):465-476

Noam EM (1982) Demand-functions and the valuation of public-goods. Public Choice 38(3):271-280

Oates W (1972) Fiscal federalism. Harcourt, Brace

OMSP (2002) Gemeindedaten. Office of Municipalities and Spatial Planning, Canton of Bern, Switzerland (Data provided in the Internet, accessed: July 2005)

Palmquist RB, Roka FM, Vukina T (1997) Hog operations, environmental effects, and residential property values. Land Econ 73(1):114-124

Parsons GR (1991) A note on choice of residential location in travel cost demand models. Land Econ 67(3):360-364

Parsons GR, Platinga AJ, Boyle KJ (2000) Narrow choice sets in a random utility model of recreation demand. Land Econ 76(1):86-99

Pate J, Loomis J (1997) The effect of distance on willingness to pay values: a case study of wetlands and salmon in California. Ecol Econ 20(3):199-207

Phaneuf D, Smith VK (2005) Recreation demand models. In: Maler KG, Vincent J (eds) Handbook of environmental economics 2. North-Holland, Amsterdam, pp 672-761

Ready RC, Abdalla CW (2005) The amenity and disamenity impacts of agriculture: estimates from a hedonic pricing model. Am J Agric Econ 87(2):314-326

Rollins K, Lyke A (1998) The case for diminishing marginal existence values. J Environ Econ Manag 36:324344

Rubinfeld DL (1977) Voting in a local school election-micro-analysis. Rev Econ Stat 59(1):30-42

Schläpfer F, Hanley N (2003) Do local landscape patterns affect the demand for landscape amenities protection? J Agric Econ 54(1):21-34

Schläpfer F, Hanley N (2006) Contingent valuation and collective choice. Kyklos 59:115-135

Schläpfer F, Witzig PJ (2006) Public support for river restoration funding in relation to local river ecomorphology, population density, and mean income. Water Resour Res 42(12):W12412

Schmidheiny K (2006) Income segregation and local progressive taxation: Empirical evidence from Switzerland. J Public Econ 90(3):429-458

Smith VK, Kopp R (1980) The spatial limits of the travel cost recreation demand model. Land Econ 56(1):6472

Smith VK, Osborne LL (1996) Do contingent valuation estimates pass a "scope" test? A meta-analysis. J Environ Econ Manag 31(3):287-301

Smith VK (1993) Nonmarket valuation of environmental resources — an interpretive appraisal. Land Econ 69(1):1-26

Swisstopo (1999) GEOSTAT Datasets GG25, GN5, GRENZ5, and PK25. Swisstopo (Federal Office of Topography), Bern, Switzerland

Taylor AE (1955) Advanced calculus. Blaisdell, Waltham

Vossler CA, Kerkvliet J (2003) A criterion validity test of the contingent valuation method: comparing hypothetical and actual voting behavior for a public good. J Environ Econ Manag 45:631-649

WSPL (2003) OEKOMORPH. Ökologie der Fliessgewässer. Produktebeschreibung. Water and Soil Protection Laboratory and Office of Water Protection and Waste Management. Bern, Switzerland

Wernli B (2001) Contraintes institutionnelles, influences contextuelles et participation aux électoins fédérales en Suisse. Haupt, Bern.

Whittington D, MacRae D (1986) The issue of standing in cost-benefit analysis. J Policy Anal Manag 5(4):665-682 